\title{
Evaluation of Sound Insulation Performance of Extruded Cement Panel with a-Hemihydrate Gypsum
}

\author{
Kim, Jin-Man Choi, Duck-Jin* \\ Department of Architectural Engineering, Kongju National University, Cheonan-si, Chongnam, 330-717, Korea
}

\begin{abstract}
The extruded cement panel, which has many advantages as a prefabricated method, has been limited in its application due to its low fire-resistance. However, an extruded cement panel produced by mixing a-hemihydrate gypsum offers dramatically improved fire-resistance and is expected to have wide-ranging applications in the construction sector as an interior material or partition wall between housing units. Sound insulation performance is very important for the partition wall between housing units. In this study, the sound insulation performance of the extruded cement panel produced through the mixture of a-hemihydrate gypsum is reviewed in order to determine its usability for a partition wall between housing units and for interior materials. Through the review it was found that the wall formed using the extruded cement panels produced by mixing the a-hemihydrate gypsum have $\star \star \star$ class in sound insulation test, equal or superior compared with the other two types of extruded cement panel walls currently available in the market.
\end{abstract}

Keywords : sound insulation performance, a-hemihydrate gypsum, extruded cement panel, partition wall

\section{Introduction}

As higher, larger and more densely populated apartment buildings are being built in Korea, more and more complaints, including civil complaints, about the residential environment of apartment buildings have been being made. For this reason, in January 2006 the Korean government enforced the Housing Performance Indicator System, which allows the general public to investigate the performance of a building in advance. The Housing Performance Indicator System has a guideline that forms the basis of an objective and guaranteed evaluation of various residential environment

Received : May 21, 2012

Revision received : July 17, 2012

Accepted : August 6, 2012

* Corresponding author : Choi, Duck-Jin

[Tel: 82-41-521-9338, E-mail: duckjini@kongju.ac.kr]

(c)2012 The Korea Institute of Building Construction, All rights reserved. factors. The grading items for boundary noise between housing units include light-weight impact sound, heavy-weight impact sound, sound in the bathroom, and boundary noise between housing units. Of these items, the boundary noise between housing units is becoming more significant with the trend of composite structures, including flat plate structures[1].

Sound insulation structures for walls are regulated by Article 14 Clause 1 of the Regulations on Standards of Housing Construction and Public Notification No. 2012-7 Housing Performance Indicator System and Management Criteria. Sound insulation performance is divided into four grades. The wall systems that satisfy sound insulation performance requirements are mostly made using a gypsum board. Gypsum board has a number of advantages, including being easy to install, provided at a reasonable price and fire-resistant 
performance. However, gypsum board also has disadvantages, including vulnerability to dampness, poor structural strength and low bearing load. For this reason, it cannot be installed in a damp place, is easily broken by external impact and has difficulty holding wall fixtures. Extruded cement panel is presented as a material that can resolve these disadvantages. An extruded cement panel is formed as a panel with continuous patterns in the axial direction that are generated by extrusion and then hardened by hydrothermal reaction. Itsstrength depends on the hydrothermal synthesis reaction. Extruded cement panels are resistant to dampness, and are easy to apply in composite structures since they are sturdy with high areal density. However, if they are exposed to fire, hydrates are dehydrated, which triggers explosive spalling due to the internal vapor pressure caused by the vaporization of hydrates. For this reason, the extruded cement panel has its limited applications in terms of partition walls or boundary walls between housing units in high-rise or large buildings, since safety is considered more significant in these building types than in other.

For this reason, we have conducted diverse studies to develop an extruded panel that causes no explosive spalling, and ultimately focused on one using a-hemihydrate gypsum. The extruding panel satisfies strength and dimension stability requirements, and has been reported in a previous paper[2] as being fire-resistant for two hours with no explosive spalling. This paper examines the required sound insulation of the extruded cement panel produced using a-hemihydrate gypsum when it is applied as interior material or partition wall between housing units. The sound insulation performance of the panel was examined in a standardized reverberation chamber and the simulation chamber of an actual residential space by using the panel only, and a composite panel made of insulation and air layer based on the panel. The sound insulation class of the extruded panel with a-hemihydrate gypsum was evaluated to estimate the applicability of the extruded panel to the housing units.

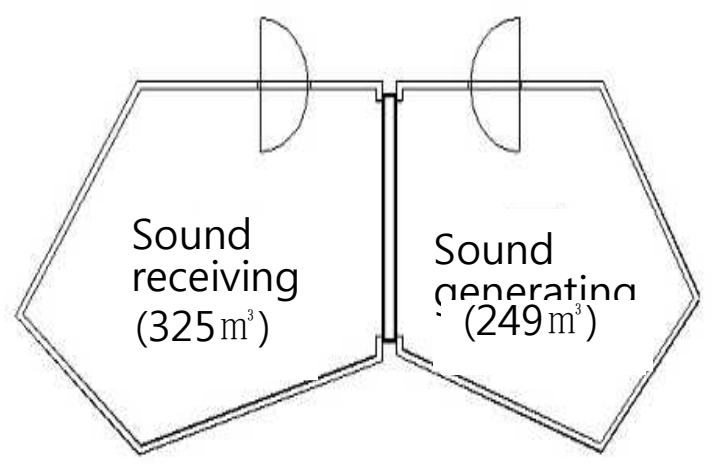

Figure 1. Floor plan of the reverberation chamber of room type I

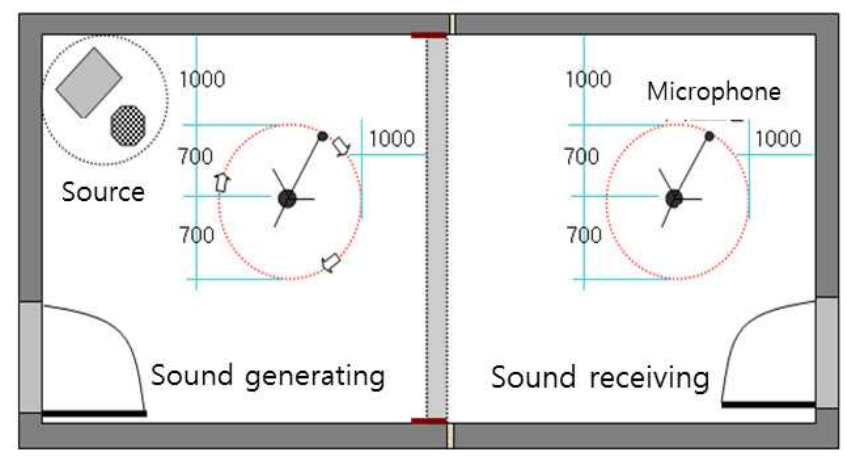

Figure 2. Floor plan of the reverberation chamber of room type ॥

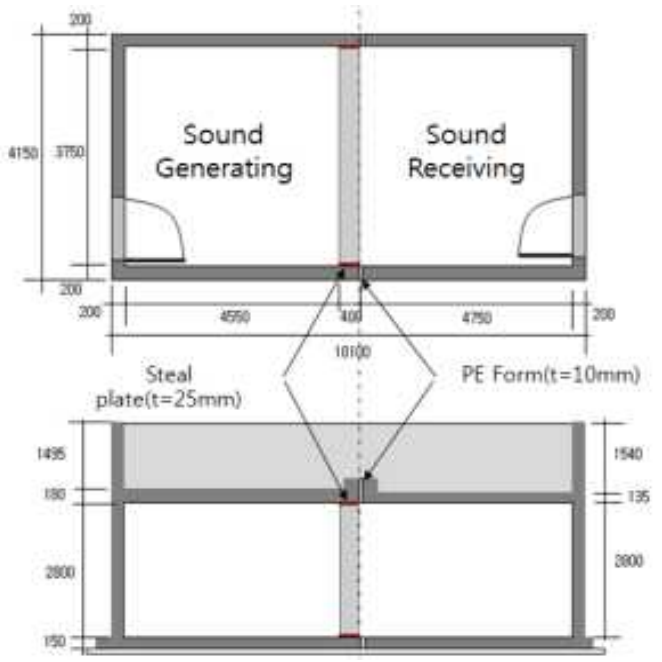

Figure 3. Design condition of room type ॥ 


\section{Experiment plan and method}

\subsection{Experiment plan}

The goal of this study is to understand the sound insulation performance of the extruded panel made with a-hemihydrate gypsum. As indicated in Table 1, the sound insulation performance was measured by difference in flat structure, type and shape of the panel used in this study.

Table 1. Design of Experiments

\begin{tabular}{|c|c|c|c|c|}
\hline \multicolumn{4}{|c|}{ Factors } & \multirow{2}{*}{$\begin{array}{l}\text { Test } \\
\text { Item } \\
\text { Test } \\
\text { Item }\end{array}$} \\
\hline \multicolumn{2}{|c|}{ Types of Panel } & $\begin{array}{l}\text { Type of } \\
\text { Module }\end{array}$ & Test Room & \\
\hline $\begin{array}{l}\text { Extrudi } \\
\text { ng } \\
\text { panel } \\
\text { develop } \\
\text { ed }\end{array}$ & $\begin{array}{c}\text { Hollowed } \\
\text { 35THollo } \\
\text { wed 50T } \\
\text { Insulation } \\
\text { 50T }\end{array}$ & $\begin{array}{l}\text { Panel } \\
\text { Wall } \\
\text { Module }\end{array}$ & $\begin{array}{c}\text { Type } 1 \text { (Standard } \\
\text { Insulation Room) } \\
\text { Type 2(Real } \\
\text { Habitat Model) }\end{array}$ & $\begin{array}{l}\text { Insulati } \\
\text { on } \\
\text { Perfor } \\
\text { mance }\end{array}$ \\
\hline Control & $\begin{array}{l}\mathrm{T}-\mathrm{C} \\
\mathrm{A}-\mathrm{C}\end{array}$ & $\begin{array}{c}\text { Panel } \\
\text { Wall } \\
\text { Module }\end{array}$ & $\begin{array}{c}\text { Type 1(Standard } \\
\text { Insulation Room) } \\
\text { Type 2(Real } \\
\text { Habitat Model) }\end{array}$ & $\begin{array}{l}\text { Insulati } \\
\text { on } \\
\text { Perfor } \\
\text { mance }\end{array}$ \\
\hline
\end{tabular}

Three types of panel with a-hemihydrate were used in the experiments: 35mm-thick and $50 \mathrm{~mm}$-thick panels with air layer and 50mm-thick panel developed for sound insulation. They were compared to the light-weight concrete sandwich panel of Company $\mathrm{T}$ and the concrete panel of Company A. A comparative analysis was conducted of the panels above following KS F 2862:2002 "Rating of Airborne Sound Insulation in Building and of Building Elements"

\subsection{Experiment method}

\subsubsection{Reverberation chamber and the test rig}

The sound insulation characteristics and performance of a-hemihydrate gypsum were measured based on KS F 2808:2001 Rating of Airborne Sound Insulation in Building and of Building Elements in two types of chamber: Type I for the standardized sound insulation performance evaluation and Type II for the simulated space of actual residential space[3].

Room Type I consists of two transformed pentagon-shaped rooms with different actual capacity connected to each other on a wall, which is a standard chamber generally used in sound insulation performance tests. The standard temperature range is between $8^{\circ} \mathrm{C}$ and $12^{\circ} \mathrm{C}$, and

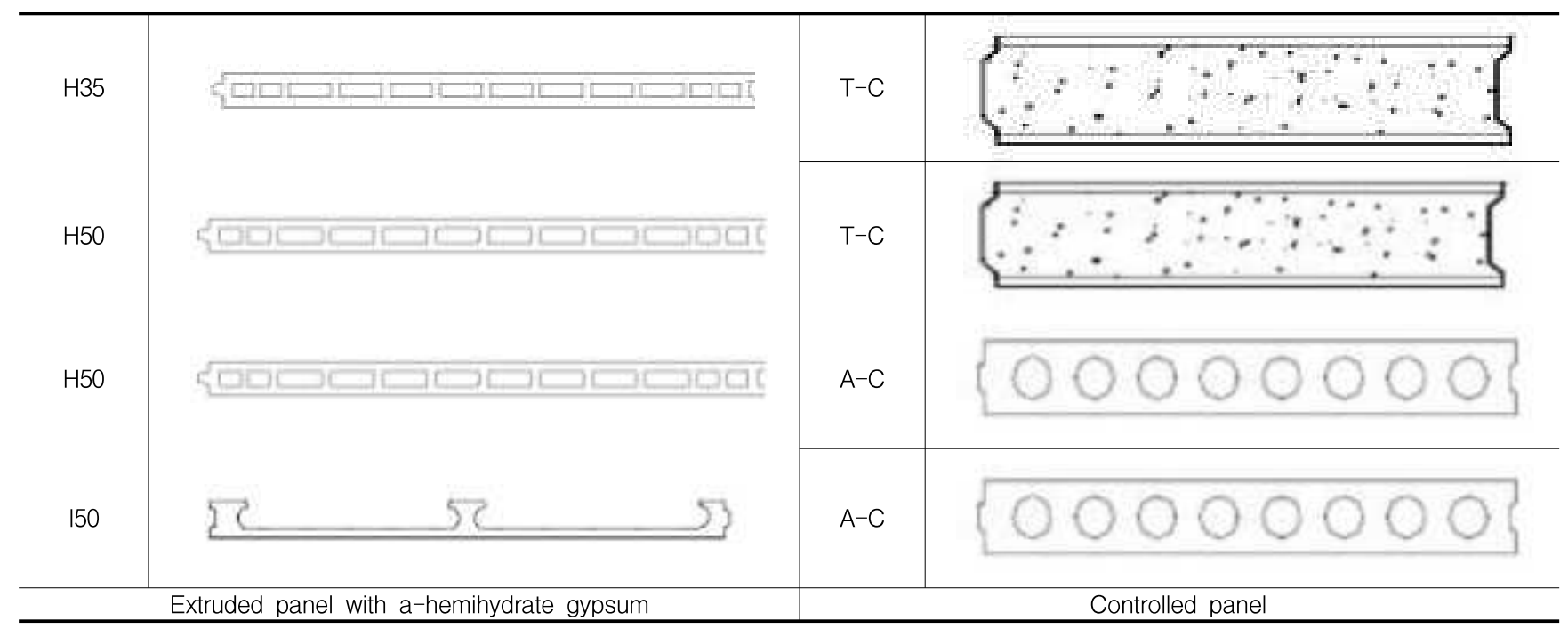

Figure 4. Section of panel used in sound insulation test 
Table 2. Specifications of measuring equipment

\begin{tabular}{|c|c|c|c|}
\hline \multicolumn{2}{|r|}{ Classification } & Room type I & Room type II \\
\hline Real time analyzer & Name & PAK MKII, Germany & SA-01, RION \\
\hline \multirow{4}{*}{ Microphone } & Name & G.R.A.S 40AE, Denmark & UC53A, RION \\
\hline & Sensitivity & $50 \mathrm{mv} / \mathrm{Pa}$ & 28 \\
\hline & Frequency range & $3.15 \mathrm{~Hz} \sim 20 \mathrm{kHz}$ & $10 \mathrm{~Hz}-20 \mathrm{kHz}$ \\
\hline & Dynamic range & $15 \sim 146 \mathrm{~dB}$ & 105 \\
\hline \multirow{3}{*}{ Sound level calibrator } & Name & \multicolumn{2}{|c|}{ NC-74, RION } \\
\hline & Frequency & \multicolumn{2}{|c|}{$1000 \mathrm{~Hz} \pm 20 \mathrm{~Hz}$} \\
\hline & Sound pressure level & \multicolumn{2}{|c|}{$94 \mathrm{~dB} \pm 0.3 \mathrm{~dB}$} \\
\hline \multirow{4}{*}{ Amplifier } & Name & XTI-4000, Crown & SPA600, VASCOM \\
\hline & Sensitivity for full rated power at $4 \mathrm{ohms}$ & $1.4 \mathrm{~V}$ & $1.5 \mathrm{~V}$ \\
\hline & Frequency response & $0 /-1 \mathrm{~dB}$ & 3 \\
\hline & Signal to noise ratio & $100 \mathrm{~dB}$ & $92 \mathrm{~dB}$ \\
\hline Speaker & Name & JBL, USA & FP120, CESVA \\
\hline
\end{tabular}

the standard humidity is between $\mathrm{RH} 45 \% \sim 55 \%$, and in terms of the volume of the reverberation chamber for measuring sound reduction coefficient (sound transmission loss), the sound generating reverberation chamber is $249 \mathrm{~m}^{3}$ and the sound receiving reverberation chamber is $325 \mathrm{~m}^{3}$.

The Room Type II is a simulation chamber of a living room or bedroom of an apartment, and Figure 2 shows the floor plan of Room Type II. The room was made using reinforced concrete to have $200 \mathrm{~mm}$-thick walls that satisfy the specifications stipulated in the measurement criteria, including dimension ratio and insulation of a room. To insulate bypass sound, 10mm-thick PE(polyethylene) form was inserted between the sound generating room and the sound receiving room. The detailed design standard is illustrated in Figure 3.

The specimen was installed in the frame (width $3.5 \mathrm{~m} x$ length $3.0 \mathrm{~m}$, area: $10.5 \mathrm{~m}^{2}$ opening) as shown in Figure 6. The gap between the frame and the panel was finished using a sealing material, and it was used in the test. . The specifications of the test rig used in the test are indicated in Table 2.

\subsubsection{Panel and wall composition}

Sectional views of 5 different types of panel used in the tests are shown in figure 5. The extruded panels used to conduct performance tests were 35mm-thick H-type panel (hereinafter H35) and 50mm-thick panel (hereinafter H50), and 50mm-thick I-type panel with a $100 \mathrm{~mm}$-thick hollow section cut in the lateral direction. The panels used for comparison were the $50 \mathrm{~mm}$-thick light-weight concrete sandwich panel of Company $\mathrm{T}$ with density of $0.78 \mathrm{~cm} / \mathrm{g}$ and weight of $39 \mathrm{~kg} / \mathrm{m}^{2}$, which was covered with pressed cement on the surface, and the $75 \mathrm{~mm}$-thick vibration concrete panel of Company A with density of $1.92 \mathrm{~cm}^{3} / \mathrm{g}$ and weight of $85 \mathrm{~kg} / \mathrm{m}^{2}$.

The $\mathrm{T}-\mathrm{C}$ module used as the standard of comparison was made by placing a sandwich panel with porous concrete covered with pressed cement plates and 50mm-thick insulation and 50mm-thick air layer inside of the composite panel, totaling $200 \mathrm{~mm}$ in thickness. The A-C module was made of $75 \mathrm{~mm}$-thick perforated concrete panel as the core material, and 25mm-thick insulation and plaster board were attached to it, totaling $200 \mathrm{~mm}$ in thickness. 


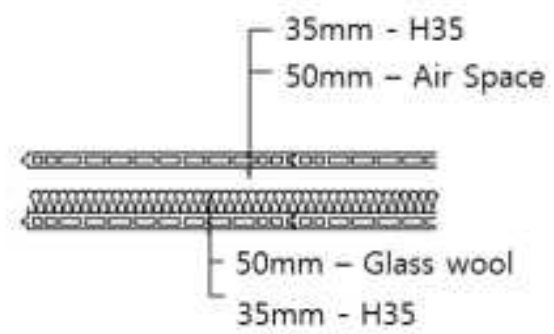

(a) Sectional view of $\mathrm{H} 35 \mathrm{~W}$ wall module

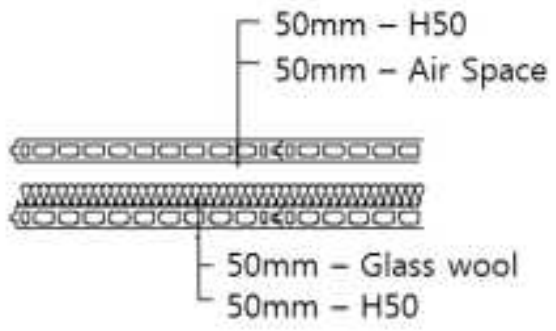

(b) Sectional view of H5OW wall module

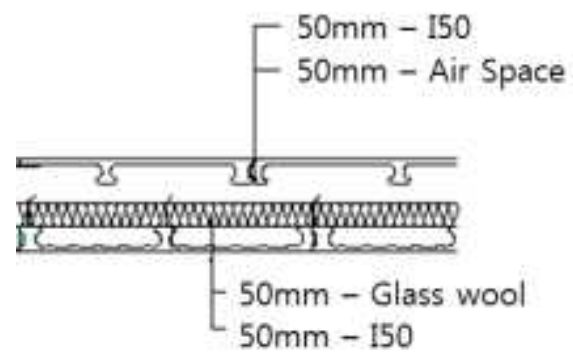

(c) Sectional view of $150 \mathrm{~W}$ wall module

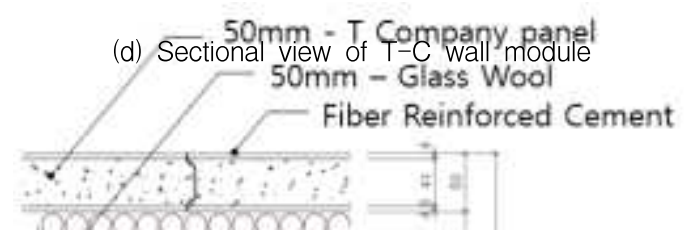

(e) Sectional view of $4.5 \mathrm{~mm}$ wall Plaster board(2EA) $11.5 \mathrm{~mm}$ Air Space $11.5 \mathrm{~mm}$ Air Space $-25 \mathrm{~mm}$ Rock wool - $75 \mathrm{~mm}$ A Company panel - $25 \mathrm{~mm}$ Rock wool

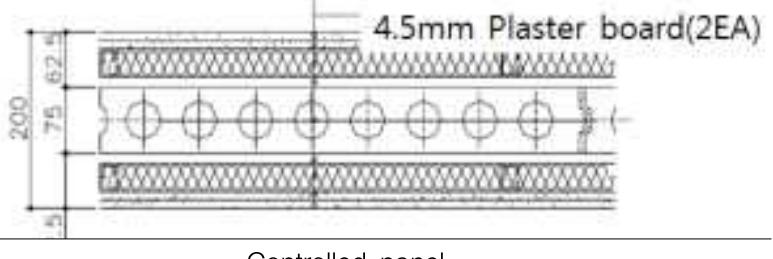

Controlled panel

Figure 5. Sectional views of 5 different types of panel used in the tests

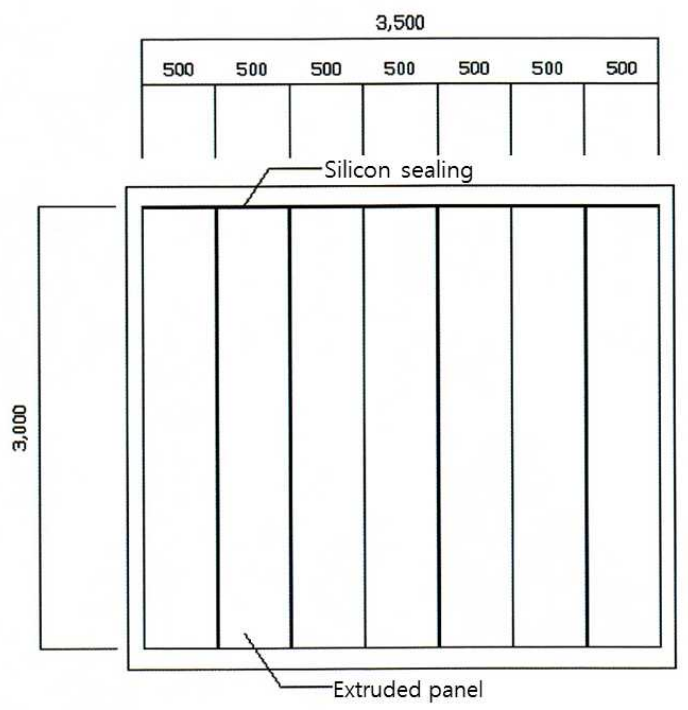

(a) Assembly drawing
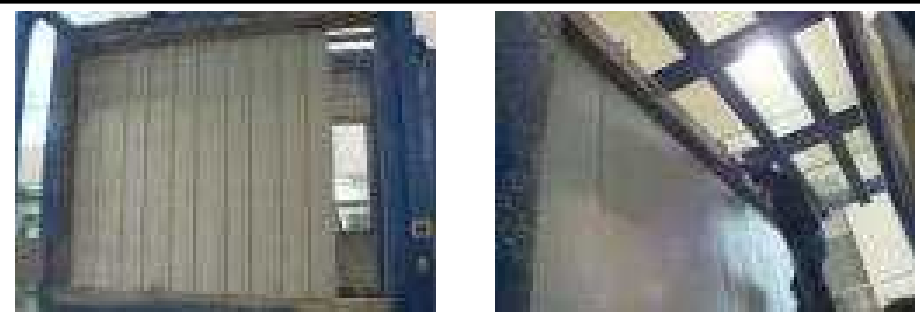

(b) Panel installing
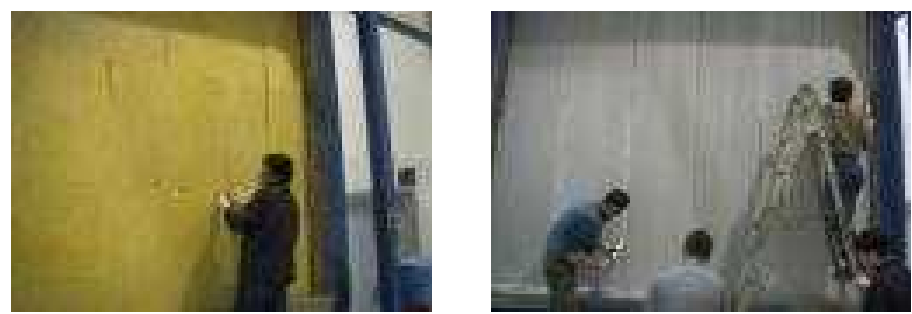

(c) Sound absorbing material

(d) Sealing

Figure 6. Panel assembly drawing and installing process 


\subsubsection{Calculation of sound insulation performance}

To evaluate the sound insulation performance, the specimens were installed between the sound generating room and the sound receiving room based on KS F 2808:2001, and each were measured in terms of average sound pressure level, sound absorbing power and sound reduction coefficient. To measure the average sound pressure level, 5 points were selected $0.7 \mathrm{~m}$ away from the boundary of the sound generating and sound receiving rooms, at least $1 \mathrm{~m}$ away from the sound source in the sound generating room and at least
$0.7 \mathrm{~m}$ away from the microphone. In terms of single number quantity (Rw), the KS standard curve corresponding to the curve that connected the measured values was moved up and down in the unit of $1 \mathrm{~dB} .16$ sound values were measured in $1 / 3$ octave band, and the standard curve was moved as much as possible within the range where the sum of the values found to be smaller than the standard curve did not exceed $32 \mathrm{~dB}$. The sound reduction coefficient(R) was obtained at $500 \mathrm{~Hz}$ in the standard curve moved.

The term and symbol of the single-number
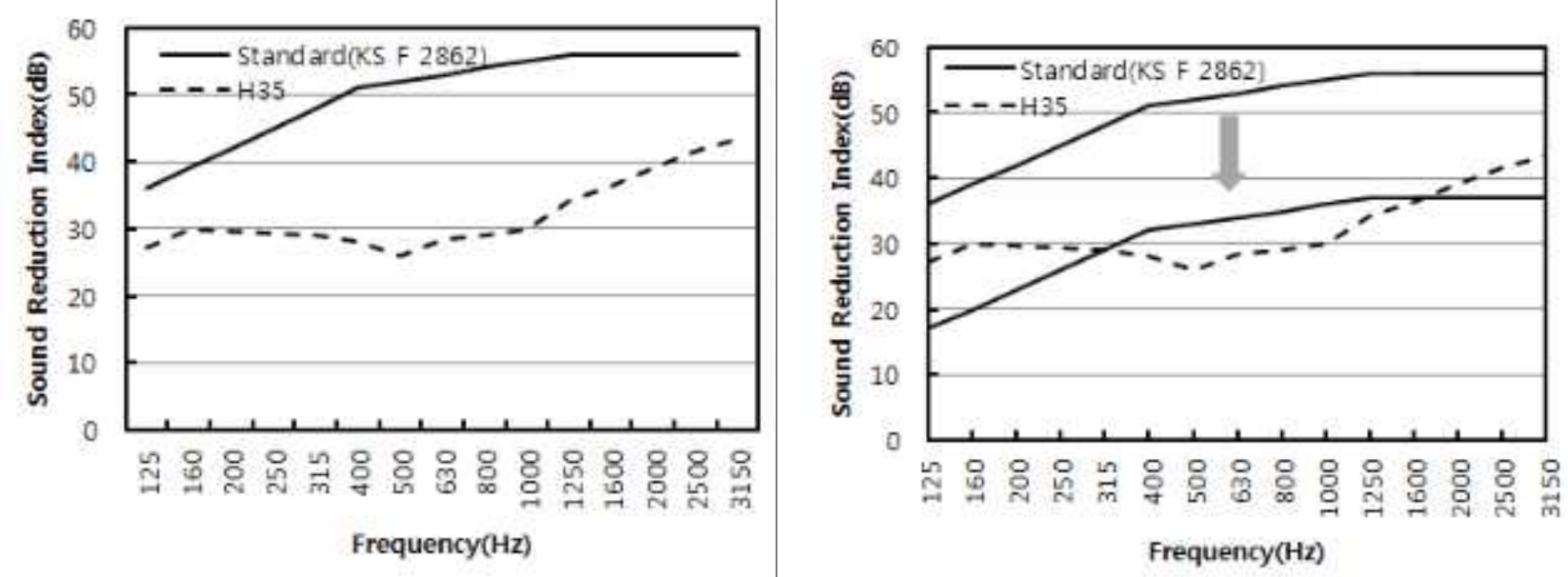

$<$ Step 1>

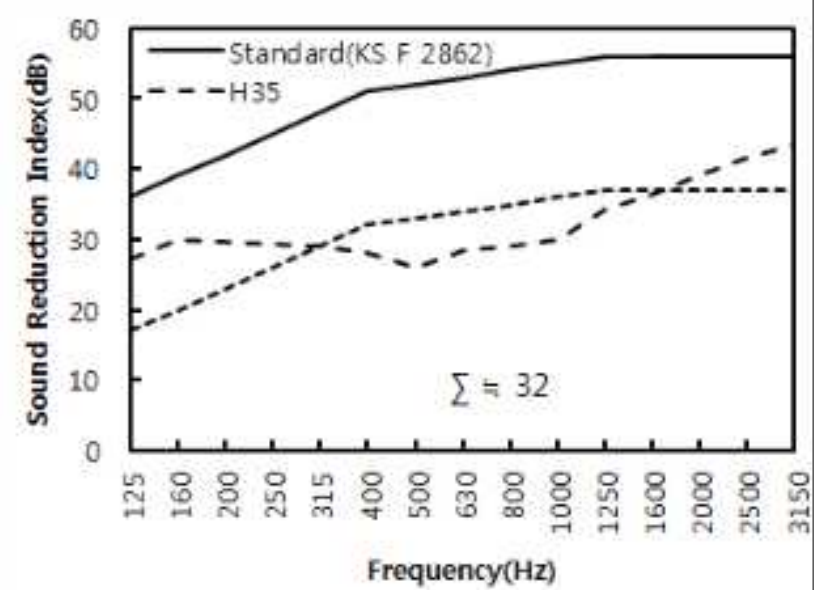

$<$ Step 2>

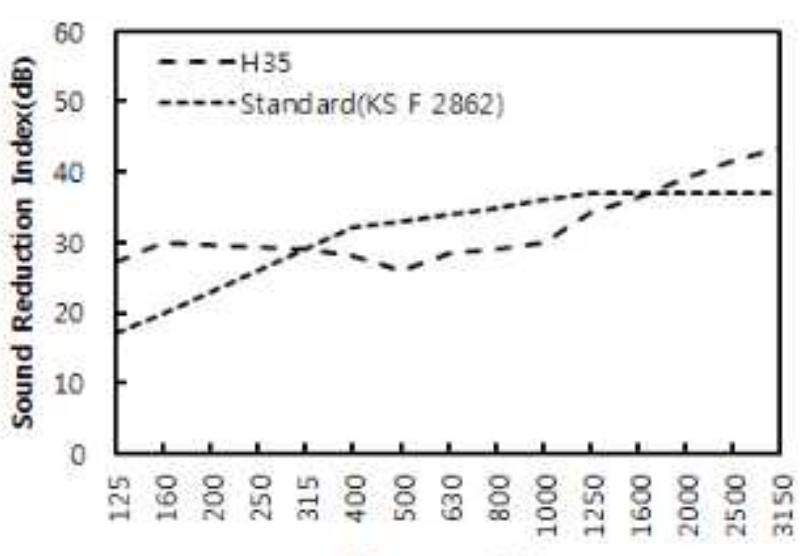

Frequency $(\mathrm{Hz})$

$<$ Step 3>

$<$ Step 4>

Figure 7. Calculation methods of single-number quantity for airvorne sound(Ex. H35) 
quantity for airborne sound vary depending on measurement type. Using the single-number quantity set in the Housing Performance Indicator System and Management Criteria notified by the Ministry of Construction and Transportation, the sound insulation performance was examined. The spectrum constant, $\mathrm{C}$, is a value expressed by adding to the single number quantity $(\mathrm{Rw})$ when considering the spectrum of a specific note. Spectrum 1(C) is a constant related with noise sources in the middle and upper registers such as daily living noise, expressways and jet planes. Spectrum $2\left(\mathrm{C}_{\mathrm{tr}}\right)$ is a constant related with noise sources in the lower register, such as city roads and low-speed railroads. Spectrum constants ( $\mathrm{C}$ and $\mathrm{C}_{\mathrm{tr}}$ ) were calculated based on the spectrums given in KS F 2862[4].

$$
C=X_{A, 1}-X_{W}, C_{t r}=X_{A, 2}-X_{W}
$$

Here, $\quad X_{W}$ : single number quantity(weighted sound reduction coefficient. Rw)

$$
\begin{aligned}
& X_{A, 1}=-10 \log \sum 10^{\left(L_{i 1}-X_{i}\right) / 10}, \\
& X_{A, 2}=-10 \log \sum 10^{\left(L_{i 2}-X_{i}\right) / 10}
\end{aligned}
$$

$X_{i}$ : sound reduction coefficient in the $i^{\text {th }}$ frequency band
Here, $i$ : octave band indicator

$L_{i 1}$ : a value given in KS F 2862 Table 4 in respect to the $i^{\text {th }}$ frequency band of Spectrum 1

$L_{i 2}$ : a value given in KS F 2862 Table 4 in respect to the $i^{\text {th }}$ frequency band of Spectrum 2

The value of sound transmission loss calculated using the equation above was determined based on the sound insulation performance grade of the boundary wall between housing units stipulated in Annex 1 of Public Notification No. 2012-7 "Housing Performance Indicator System and Management Criteria" from the Ministry of Construction and Transportation and "Structural Sound Insulation Requirements and Management Criteria for Walls" from the Ministry of Construction and Transportation[5].

Table 4. Sound insulation performance grades for apartment housing

\begin{tabular}{cc}
\hline Grade & Single number quantity \\
$\star \star \star \star$ & $63=\mathrm{Rw}+\mathrm{C}$ \\
$\star \star \star$ & $58=\mathrm{Rw}+\mathrm{C}<63$ \\
$\star \star$ & $53=\mathrm{Rw}+\mathrm{C}<58$ \\
$\star$ & $48=\mathrm{Rw}+\mathrm{C}<53$ \\
\hline
\end{tabular}

Table 5. Data acquired by sound insulation performance test

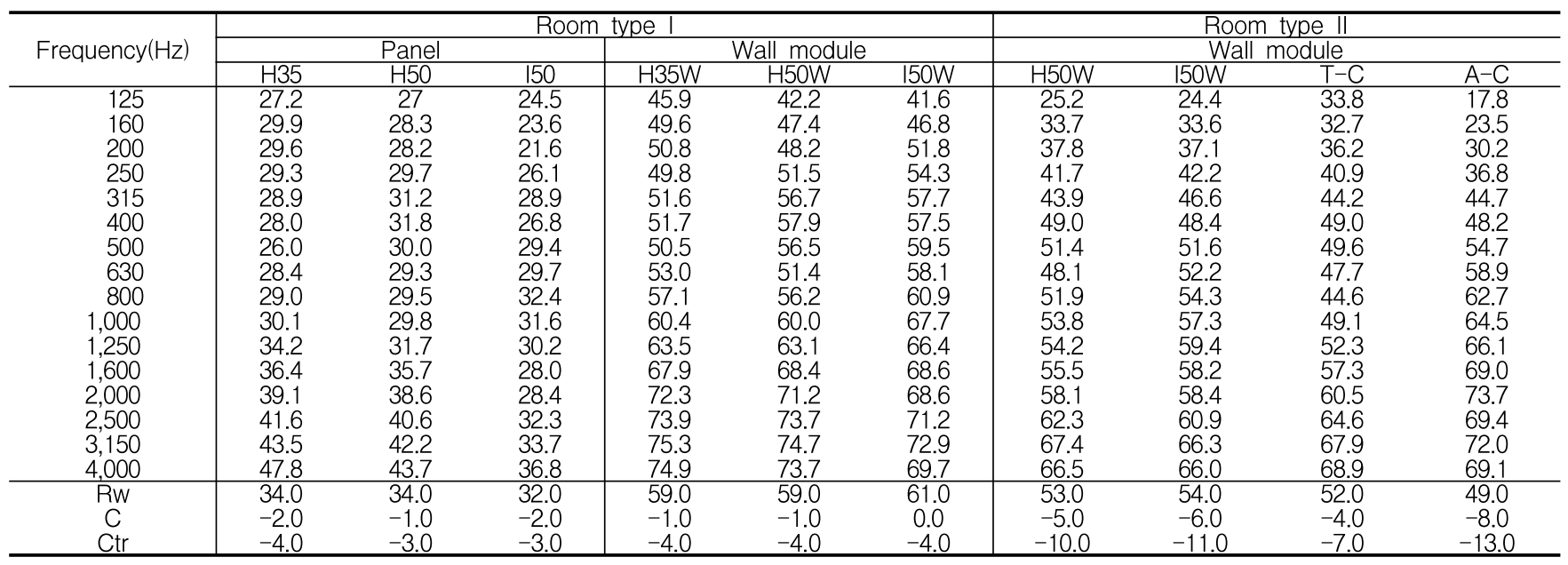




\section{Test results}

The sound reduction coefficients measured from 16 octave bands within $125 \mathrm{~Hz}$ to $4,000 \mathrm{~Hz}$ are divided by each test factor and indicated in Table 5. In Room Type I for standard sound insulation test, the individual panels and the three types of wall module made with the panel as the main component were tested, and in Room Type II for the simulation chamber of an actual residential space, 4 types of wall module were tested.

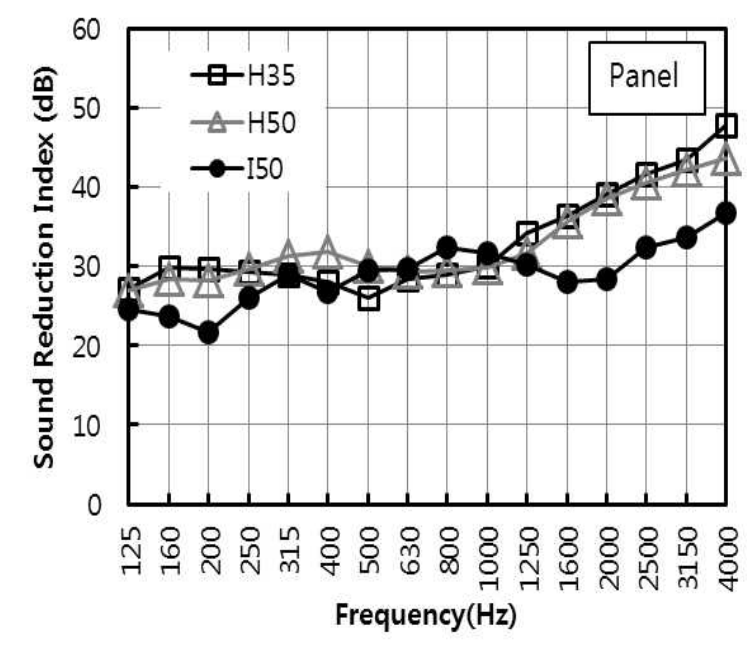

Figure 8. Sound reduction index according to section shape of extruded panel

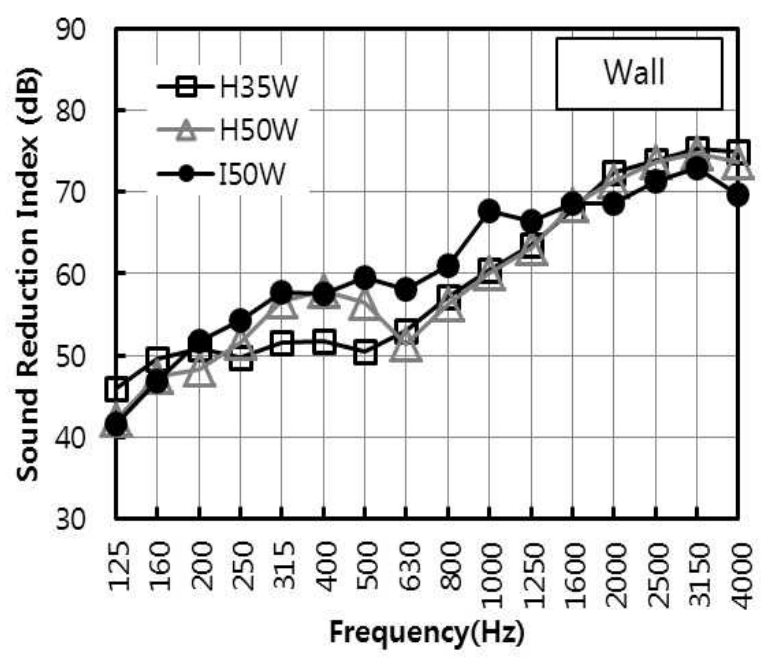

Figure 9. Sound reduction index according to wall type

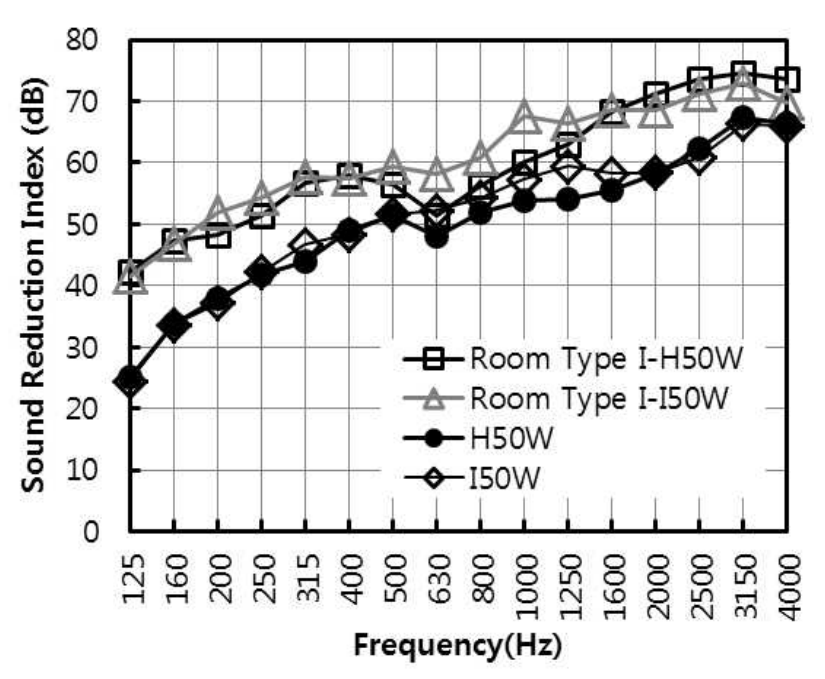

Figure 10. Comparison of sound reduction index between room type I and room type II

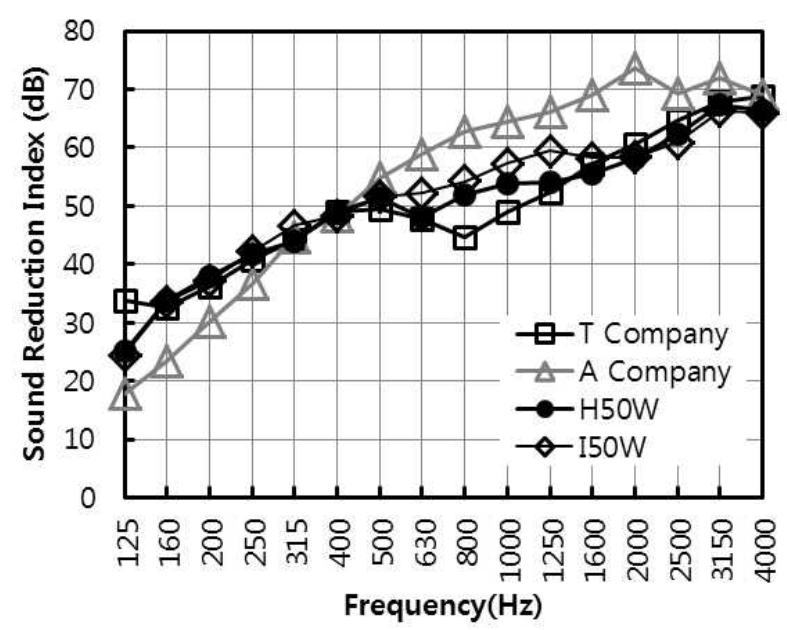

Figure 11. Comparison of sound reduction index between commercial products and this study

\subsection{Sound insulation performance of individual panel in the standard sound insulation chamber (Room Type I)}

Figure 8 illustrates the results of tests of three types of extruded cement panel with a-hemihydrate gypsum with $35 \mathrm{~mm} \mathrm{H}$ sectional thickness (H35), $50 \mathrm{~mm} \mathrm{H}$ sectional thickness (H50), and $50 \mathrm{~mm} \mathrm{I}$ sectional thickness (I50), in the standard insulation test chamber (Room Type I). From the test results, it is found that after taking spectrum constant into account, the single number quantity of H50, H35 
and $150(\mathrm{Rw}+\mathrm{C})$ stood at $32 \mathrm{~dB}, 31 \mathrm{~dB}$ and $30 \mathrm{~dB}$, respectively. The panels with air space, H50 and H35, showed sound transmission loss in the frequency range between $125 \mathrm{~Hz}$ and $1000 \mathrm{~Hz}$, which is almost similar to that of I50; however, they showed higher loss in frequency ranges other than I50, and in particular showed a much greater difference in the frequency range of $1600 \mathrm{~Hz}$ or higher. From the analysis, it is revealed that the panels with an air layer showed better performance than the panel with no air space.

\subsection{Sound insulation performance of wall modules in the standard insulation test chamber (Room Type I)}

The sound insulation performance of the wall modules made using each extruded panel with a-hemihydrate gypsum as cover with air layer and insulation inside was evaluated, and is shown in Figure 9. From the analysis, taking the spectrum constant into account, the single number quantity $(\mathrm{Rw}+\mathrm{C})$ stood at $58 \mathrm{~dB}, 58 \mathrm{~dB}$ and $61 \mathrm{~dB}$, respectively. In terms of sound reduction coefficient by panel type, I50 showed better sound transmission loss than wall modules of H35W and H50W that had air layer in frequency ranges other than $160 \mathrm{~Hz}$ or lower or $1600 \mathrm{~Hz}$ or higher, which was the opposite of the test results of individual panels. The thinner and wider panel structure is believed to have helped increase the noise reduction effect.

\subsection{Sound insulation performance under conditions of Room Type I and Room Type II}

The results of a comparative analysis of sound insulation performance under conditions of Room Type I and Room Type II are shown in Figure 10. The tests were performed for the modules made with the cover of $50 \mathrm{~mm}$-thick $\mathrm{H}$ panel with an air layer and I panel with no air layer. Both H50W and I50W showed a lower single number quantity in the standard test chamber, Room Type I, than in the simulation chamber of an actual residential space, Room Type II. The single number quantity was measured at $10 \mathrm{~dB}$ in $\mathrm{H} 50 \mathrm{~W}$ and at $13 \mathrm{~dB}$ in I50W. The difference was shown to be greater in the panels with no air layer than in the panels with air layer. The bypass noise is believed to be the cause of these results, because the bypass noise was not completely blocked in Room Type II due to its structural characteristics of walls and floor.

\subsection{Comparison of sound insulation performance between the existing panels and the newly developed panels in an actual residential space}

The results of a comparative analysis of sound insulation performance between the conventional wall systems of Company $\mathrm{T}$ and Company $\mathrm{A}$ and H50W and I50W in Room Type II are shown in Figure 11. The existing products of Company $\mathrm{T}$ and Company A used as the standard of comparison showed better performance. The product of Company $\mathrm{T}$ was better at frequencies lower than $500 \mathrm{~Hz}$, while the product of company A was better at $500 \mathrm{~Hz}$ or higher. The panels developed in this study showed similar characteristics overall to those of the product of Company A, though slightly different in the range between $630 \mathrm{~Hz}$ and $1250 \mathrm{~Hz}$, and it was determined that the sound insulation performance of the panels developed in this study was good in the low frequency range.

Likewise, the extruded panels manufactured using a-hemihydrate gypsum are shown to have had a similar level of sound insulation performance compared to the existing products, and they can be utilized in an actual residential space. 


\subsection{Sound insulation performance evaluation of the developed panels}

Figure 12 shows the results of an analysis of sound insulation performance based on the sound insulation performance of a boundary wall between housing units. Under the condition of Room Type I, the individual panels did not provide sufficient sound insulation performance. However, the sound insulation performance was evaluated to be

class in all three types of wall module developed by combining the panels with air layer and insulation, which can be applied to an actual residential space. However, the sound insulation performance was evaluated to be $\star \star$ class under the condition of Room type II due to bypass sound, as mentioned previously. Nevertheless, the panels developed in this study showed similar or better sound insulation performance compared to the existing products of two companies, and on this basis they are believed to have a competitive edge as sound insulation materials.

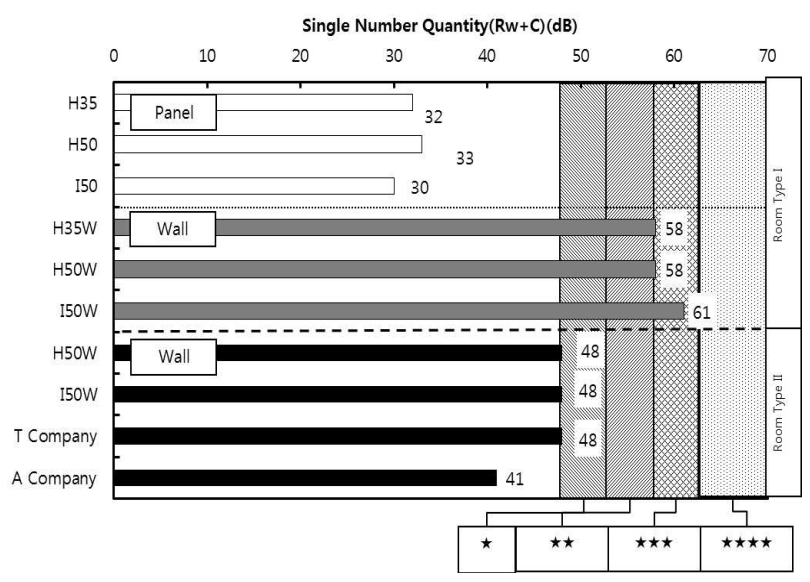

Figure 12. Grade of sound insulation performance

\section{Conclusions}

This paper is part of ongoing research to examine the applicability of extruded cement panels with a-hemihydrate gypsum, known to improve fire-resistance, to interior material and partition walls between housing units. To accomplish this, sound insulation performance was analyzed and the findings of this research are as follows:

1) The sound insulation performance was analyzed differently depending on test factor: sectional shape or wall composition, which is believed to have been affected by areal density, sectional shape, air layer and thickness of the wall, and the sound reduction effect was developed in a complex manner. For this reason, we believe that the factors above should be considered in a subsequent study in order to gain a clearer understanding of the sound insulation performance of extruded panels with a-hemihydrate gypsum.

2) Through tests of sound insulation performance with the same panels under different room conditions, it is found that the sound insulation of a boundary wall between housing units was evaluated to be about two grades lower in the simulation chamber of an actual residential space, Room Type II, than in the standard sound insulation test chamber, Room Type I. For this reason, the sound insulation performance should be examined under an actual residential condition that a resident can actually experience.

3) The extruded panels with a-hemihydrate gypsum developed in this study showed sound insulation performance equivalent to or better than that of two types of existing panels, on which basis they were confirmed as having sufficient sound insulation performance to be utilized as partition walls between housing units.

\section{Acknowledgement}

This work was supported by Business for Cooperative R\&D between Industry, Academy, and 
Research Institute funded Korea Small and Medium

Business Administration in 2012(Grants No. C00-56377) and by the R\&D Center for Valuable Recycling (Global-Top Environmental Technology Development Program) funded by the Ministry of Environment(Project No.:11-C21-ID).

\section{References}

1. Nam JC. Development of an Inter-Household Light Weight Wall for Improvement of the sound reduction in the Apartments [dissertation]. Seoul (Korea): University of Hanyang. 2007. p. 1-2

2. Kim JM, Kang SP, Choi DJ, Ra JM. Hydration Behavior and Fire-Resistance Property of Cement Mortars Mixed with Various Types of Gypsum. Korea. Journal of Architectural Institute of Korea 2010 December;26(12):128-13.

3. Korean Standards Association. KS F 2862 Rating of Airborne Sound Insulation in Buildings and of Building Elements. Seoul (Korea): KSA. 2002.

4. Ministry of Construction \& Transportation. Control Standard of Housing Performance Grade. Gwacheon (Korea): Ministry of Construction \& Transportation. 2012.

5. Jang GS, Lee TG, Song MJ, Kim SW. Classification of Transmission Loss for Steel Panel and Extrusion Concrete Panel. Journal of Korean Society for Noise and Vibration Engineering. 2003 November;Autumn conference:864-9.

6. Korean Standards Association. KS F 2808 Laboratory Measurements of Airborne Sound Insulation of Building Elements: KSA. 2011.

7. Kang C. Experimental Study on the Development of Light Weight Non-Bearing Wall using Bottom Ash [dissertation]. Kongju (Korea): University of Kongju; 2006. p. 57-9.

8. Kim KW, Choi HJ, Yang KS. Methods of Measuring Sound Insulation Performance of Building. Journal of Korean Society for Noise and Vibration Engineering. 2010 May;Spring confernce:325-6.

9. Baek, SK, Go JC, Lee JI, Kim HB, Chang CS. Analysis and Evaluation of Sound Reduction Performance of Drywall System. Journal of Korean Society for Noise and Vibration Engineering 2009 November;Autumn conference:727-32.

10. Park HK. Analysis of characteristics and User's Evaluation for Lightweight Panel in Apartment. Journal of Korea Institute of Building Construction 2010 February;10(1):181-91.
11. UM TH, Kim YT. Properties of Concrete Panel made by Light Weight Aggregates. Journal of Korean Ceramic Society 2004 March;41(3):221-8. 